\begin{tabular}{|c|l|}
\hline Title & $\begin{array}{l}\text { Radiosensitization of tumor cells through endoplasmic reticulum stress induced by PEGylated nanogel containing gold } \\
\text { nanoparticles }\end{array}$ \\
\hline Author(s) & $\begin{array}{l}\text { Yasui, Hironobu; Takeuchi, Ryo; Nagane, Masaki; Meike, Shunsuke; Nakamura, Y oshinari; Y Yamamori, Tohru; } \\
\text { Ikenaka, Y oshinori; Kon, Y asuhiro; Murotani, Hiroki; Oishi, Motoi; Nagasaki, Y ukio; Inanami, O samu }\end{array}$ \\
\hline Citation & $\begin{array}{l}\text { Cancer Letters, 347(1), 151-158 } \\
\text { https://doi.org/10.1016/.canlet.2014.02.005 }\end{array}$ \\
\hline Issue Date & 201403 \\
\hline Doc URL & http:/hdl.handle.net/2115/55287 \\
\hline Type & article (author version) \\
\hline File Information & Cancer Letters 347(2014).pdf \\
\hline
\end{tabular}

Instructions for use 


\section{Radiosensitization of tumor cells through endoplasmic reticulum stress induced by PEGylated nanogel containing gold nanoparticles}

Hironobu Yasui ${ }^{1}$, Ryo Takeuchi ${ }^{1}$, Masaki Nagane ${ }^{1}$, Shunsuke Meike ${ }^{1}$, Yoshinari Nakamura $^{1}$, Tohru Yamamori ${ }^{1}$, Yoshinori Ikenaka ${ }^{2}$, Yasuhiro Kon ${ }^{3}$, Hiroki Murotani ${ }^{4}$, Motoi Oishi ${ }^{4}$, Yukio Nagasaki $^{4} \&$ Osamu Inanami ${ }^{1 *}$

${ }^{1}$ Laboratory of Radiation Biology and ${ }^{2}$ Laboratory of Toxicology, Department of Environmental Veterinary Sciences, Graduate School of Veterinary Medicine, Hokkaido University, Sapporo 060-0818, Japan

${ }^{3}$ Laboratory of Anatomy, Department of Biomedical Sciences, Graduate School of Veterinary Medicine, Hokkaido University, Sapporo 060-0818, Japan

${ }^{4}$ Division of Materials Sciences, Faculty of Pure \& Applied Sciences, University of Tsukuba, Tsukuba 305-8573, Japan

*Author for Correspondence

Address: Kita 18, Nishi 9, Kita-ku, Sapporo, Hokkaido 060-0818, Japan.

Tel.: +81 117065235

Fax: +81 117067373

Email: inanami@vetmed.hokudai.ac.jp 


\begin{abstract}
High atomic number molecules, such as gold and platinum, are known to enhance the biological effect of X-irradiation. This study was aimed to determine the radiosensitizing potential of PEGylated nanogel containing gold nanoparticles (GNG) and the cellular mechanism involved. GNG pretreatment increased the levels of reproductive cell death and apoptosis induced by X-irradiation. GNG accumulated in cytoplasm and increased the expression of endoplasmic reticulum (ER) stress-related protein. GNG suppressed the repair capacity of DNA after X-irradiation by down-regulating DNA repair-related proteins. Our results suggest that GNG radiosensitized cells by enhancing apoptosis and impairing DNA repair capacity via ER stress induction.
\end{abstract}

\title{
Keywords
}

Apoptosis; DNA repair; Endoplasmic reticulum stress; Gold nanoparticle; Radiation 


\section{Introduction}

High atomic number materials are known to enhance the biological effects of X-irradiation. In pioneering studies, the groups of Matsudaira et al. [1] and Nath et al. [2] demonstrated that iodine and iododeoxyuridine had a radiosensitizing effect on cultured cells. In addition, gold particles (atomic number, $Z=79$ ) have been used as a more promising radiosensitizer because they have a higher $\mathrm{Z}$ number and a greater biocompatibility than iodine $(\mathrm{Z}=53)[3,4]$. Herold et al. demonstrated the radiosensitization of cells suspended in a 1\% gold particle solution $(1.5-3.0 \mu \mathrm{m}$ diameter), as well as tumors injected with gold microspheres[5]. However, it would be difficult to deliver such relatively large particles into cells as microspheres and distribute them uniformly throughout the tumor. To overcome this difficulty, many studies have attempted to apply reduced-size gold particles for the enhancement of cellular radiosensitivity. Rahman et al. [6] and Hainfeld et al. [7,8,9] demonstrated that smaller gold particles with dimensions of $1.9 \mathrm{~nm}$ were not only internalized in the treated cells in vitro, but also distributed uniformly in transplanted tumors in vivo.

Chang et al. reported that 13-nm gold nanoparticles accumulated in B16F10 melanoma cells and radiosensitized them via apoptotic induction [10].

As demonstrated in these previous studies, nonfunctionalized gold 
nanoparticles have shown some level of accumulation in tumor cells. However, gold nanoparticles still potentially achieve higher stabilization and tumor selectivity by modifying particle organization. For example, it has been reported that the PEGylated gold nanoparticle, which was conjugated with polyethylene glycol for stabilization of gold nanosol, sensitized EMT-6 breast carcinoma cells and CT26 colorectal adenocarcinoma cells to various types of ionizing radiation $(6.5 \mathrm{keV}, 8.048 \mathrm{keV}, 73 \mathrm{keV}$ and $6 \mathrm{MeV} \mathrm{X}$-rays and $3 \mathrm{MeV}$ protons) [11]. This PEGylated modification of gold nanoparticles has laid out a new strategic direction for improving their bioefficiency; however, under reduced in vivo conditions PEGylated gold nanoparticles prepared by immobilization via sulphanyl-ended PEG may not be sufficiently stable because of the replacement and/or oxidation of the Au-S linkage. Detachment of the PEG results in a decrease in its dispersion stability, as well as the non-fouling character with biocomponents. Recently, our group newly synthesized a novel gold nanogel (GNG) consisting of a PEGylated nanogel with large payloads of gold nanoparticles $(8 \mathrm{~nm}$ diameter) [12]. This type of PEGylated nanogel is composed of a cross-linked $\operatorname{poly}(2-[N, N$,-diethylamino]ethyl methacrylate) (PEAMA) gel core, and tethered PEG chains that possess an acetal group that serves as a platform for the installation of ligand molecules, as illustrated in Fig. 1. This GNG has been reported to show extremely high 
dispersion stability and unique properties such as a reversible volume phase transition in response to $\mathrm{pH}$, temperature and ionic strength [13]. The diameter of GNG particles was determined as $106 \pm 2.68 \mathrm{~nm}$ and approximately 15 gold particles were included in each PEGylated nanogel; these data were obtained using transmission electron microscopy (TEM) [12]. Note that the GNG showed an appreciably high stability under hypertonic conditions, as compared with the commercially available citrate-stabilized gold nanoparticles, because of the steric stabilization of the hydrophilic PEG chains [12]. Since each GNG possesses several to 15 gold nanoparticles in the core as stated above, the accumulation efficiency should be much higher than is achievable using PEGylated gold nanoparticles. However, the radiosensitizing effect of gold nanoparticles incorporated in a functional nanogel such as GNG has never been assessed thus far. As to the theoretical basis for the radiosensitization effect of gold particles, it is well known that high atomic number elements absorb X-rays efficiently and deposit this energy locally; this is mostly as a result of the emission of photoelectrons, Auger electrons and Compton scattering [7]. Recent reports have also provided evidence that gold nanoparticles show several biological effects, such as the production of reactive oxygen species [14], cell cycle regulation [15] and the induction of apoptosis [10]. Furthermore, Wang et al. reported that PEGylated phospholipid nanomicelles, albeit not 
containing gold particles, accumulated in the endoplasmic reticulum (ER), induced ER stress and activated the unfolded protein response (UPR), leading to apoptosis [16]. These additional actions could potentiate the radiosensitizing effect induced by physical dose absorption. In addition, inherent DNA repair capacity is one of the important factors that determines cellular radiosensitivity and is closely associated with the outcome of radiotherapy [17]. The DNA double-strand break (DSB) is the most lethal damage that is expressed among the various types of DNA lesions induced by radiation; however, two intrinsic DSB repair pathways, non-homologous end joining (NHEJ) and homologous recombination (HR), enable cells to survive. While the modulation of these pathways has the potential to elevate radiation efficiency, no study to test the effect of gold nanoparticles on DSB repair capacity has been performed to date.

In the present study, we investigated whether or not GNG enhances reproductive cell death and apoptosis induced by X-irradiation in murine squamous carcinoma SCCVII cells, human lung adenocarcinoma A549 cells and Chinese hamster V79 cells. The contribution of the physical dose enhancement to radiosensitization was examined using a Fricke chemical dosimeter. The intracellular biodistribution of GNG and ER stress were analyzed using a TEM and western blotting, respectively. Cellular DSB repair capacity was examined using the $\gamma-\mathrm{H} 2 \mathrm{AX}$ foci formation assay. 


\section{Materials \& methods}

\subsection{Materials}

The following antibodies were used for immunostaining and immunoblotting: anti-phospho-H2AX (Ser139); anti-IRE1 $\alpha$; anti-BiP (GRP78); anti-phospho-PERK; anti-PERK; anti-Calnexin; anti-Ero1-L $\alpha$ (Cell Signaling Technology, Beverly, MA, USA); anti-Actin; anti-Rad51; anti-Ku70; HRP-conjugated secondary antibodies (Santa Cruz Biotechnology, Santa Cruz, CA, USA); and Alexa Fluor 488 anti-rabbit IgG (Invitrogen, Carlsbad, CA, USA). The chemiluminescence detection kit and Western Lightning Plus-ECL was purchased from Perkin Elmer (Boston, MA, USA). Other reagents without specific descriptions were obtained from Wako Pure Chemical Co. (Tokyo, Japan).

\subsection{Synthesis of GNG}

The PEGylated nanogel with a 2 mol\% cross-link density was prepared as described previously [12]. To synthesize the PEGylated nanogel containing gold nanoparticles at a number of amino groups/number of $\mathrm{Au}$ atoms $(\mathrm{N} / \mathrm{Au})$ ratio of 1 , $\mathrm{HAuCl}_{4}$ aqueous solution was added to the PEGylated nanogel solution at final concentrations of $4.37 \mathrm{mg} / \mathrm{mL}$ and $5.97 \mathrm{mg} / \mathrm{mL}$, respectively. After the obtained GNG 
had been purified by dialysis, the resulting mixture was adjusted to a $\mathrm{pH}$ of 6.0 and stirred for $24 \mathrm{~h}$ at $60^{\circ} \mathrm{C}$. Purification was carried out by ultracentrifugation $(145,000 \mathrm{~g})$ using water to remove the unreacted $\mathrm{Au}$ (III) ions and concentrate the PEGylated GNG solution for use in in vitro experiments.

\subsection{Cell culture}

Murine squamous cell carcinoma SCCVII and Chinese hamster V79 cells were grown in $\alpha$-MEM medium (Gibco-BRL/Invitrogen) supplemented with $10 \%$ fetal bovine serum (FBS: Filtron, Brooklyn, Australia). Human lung carcinoma A549 cells were cultured with RPMI 1640 medium (Gibco-BRL/Invitrogen) containing 10\% FBS. Cells were maintained at $37^{\circ} \mathrm{C}$ in $5 \% \mathrm{CO}_{2} / 95 \%$ air.

\subsection{X-irradiation and drug treatment}

Cells attached to a $6-\mathrm{cm}$ plastic dish were treated with GNG at the indicated concentrations for $14 \mathrm{~h}$ before X-irradiation. The cells were then exposed to X-rays either in the presence or absence of GNG. X-irradiation was performed using a Shimadzu PANTAK HF-350 X-ray generator (1.0 mm Al filter; $200 \mathrm{kVp} ; 20 \mathrm{~mA}$; Shimadzu, Kyoto, Japan). 


\subsection{Clonogenic survival assay}

Proper number of V79, SCCVII or A549 cells were treated with GNG for $14 \mathrm{~h}$ at a concentration of 15,20 or $50 \mu \mathrm{g} / \mathrm{ml}$, respectively. These concentrations of GNG were sublethal and showed less than $25 \%$ toxicity. After the GNG treatment and subsequent X-irradiation, cells were placed in fresh medium and cultured for indicated period (4 days for SCCVII, 6 days for V79, and 10 days for A549). The cells were fixed, stained with Giemsa solution and scored under a microscope. Only colonies containing $>50$ cells were scored as surviving cells. After the surviving fraction at each dose was calculated with respect to the plating efficiency of the non-irradiated control, the mean \pm SE of the surviving fractions obtained from three experiments was plotted.

\subsection{Apoptotic detection by double staining with Annexin V-FITC and PI}

At $48 \mathrm{~h}$ after the treatment with X-irradiation and GNG, SCCVII cells were collected by trypsinization. The cells were stained with Annexin V-FITC and PI (Medical \& Biological Laboratories Co., Nagoya, Japan) according to the manufacturer's instruction. Analyzing the stained cells was performed using an EPICS XL flow cytometer (Beckman Coulter, Inc., Brea, CA, USA ). 


\subsection{Chemical dosimetry}

Physical dose enhancement as a result of the presence of GNG was analyzed using Fricke chemical dosimetry as previously reported with some modifications [5]. A Fricke solution was prepared using $0.4 \mathrm{~g}$ Mohr's salt $\left(\mathrm{Fe}\left[\mathrm{NH}_{4}\right]_{2}\left[\mathrm{SO}_{4}\right]_{2} \cdot 6 \mathrm{H}_{2} \mathrm{O}\right), 0.06 \mathrm{~g}$ $\mathrm{NaCl}$ and $22 \mathrm{ml}$ concentrated $\mathrm{H}_{2} \mathrm{SO}_{4}$ per $\mathrm{L}$ of distilled de-ionized water. After the Fricke solutions containing 0,20 and $50 \mu \mathrm{g} / \mathrm{ml}$ GNG were X-irradiated, absorbance at $304 \mathrm{~nm}$ of the oxidation of Fe(II) to Fe(III) in the Fricke solutions was determined using a Beckman Coulter DU-800 spectrophotometer (Beckman Coulter). To prevent GNG interfering with the spectrophotometer reading, it was removed from all samples by centrifugation at $50,000 \mathrm{~g}$ for $10 \mathrm{~min}$ prior to the determination of optical density.

\subsection{Electron microscopic analysis}

TEM analysis was performed according to our previous study [18]. After treatment with GNG and X-irradiation, cells were fixed, dehydrated and embedded in epoxy resin. Ultrathin sections $(80 \mathrm{~nm})$ were cut, mounted and stained with uranyl acetate and lead citrate; they were subjected to electron microscopic observation using a JEM-1400 Plus electron microscope (JEOL, Tokyo, Japan). 


\subsection{SDS-PAGE and western blotting}

The expressions of ER stress-related protein and DNA repair-related proteins were examined by immunoblotting according to a previous report [19].

\subsection{Immunofluorescent staining for $\gamma-\mathrm{H} 2 \mathrm{AX}$}

The cellular DNA repair capacity after the treatment with GNG was assessed by using $\gamma-\mathrm{H} 2 \mathrm{AX}$ foci formation assay according to a previous report [19].

\subsection{Statistical analysis}

All results were expressed as the mean $\pm \mathrm{SE}$. The variance ratio was estimated using the F-test and differences in means of groups were determined using Student's t-test or Welch's t-test. The minimum level of significance was set at $\mathrm{p}<0.05$. 


\section{Results}

\subsection{Effects of GNG on the radiosensitivity of tumor and immortalized cells}

To examine whether or not radiation-induced cell death was enhanced by GNG

treatment, we first performed a clonogenic survival assay for evaluating integrated multiple forms of cell death such as apoptosis, necrosis and mitotic catastrophe using various tumor cell lines and immortalized cells. SCCVII, A549 and V79 cells were pretreated with GNG for $14 \mathrm{~h}$ and exposed to X-rays in the presence of GNG. Fig. 2A shows the survival curves for SCCVII, A549 and V79 cells. The treatment with GNG suppressed clonogenic cell survival in all cell lines tested, and the sensitizer enhancement ratio judged in terms of a $10 \%$ lethal dose (which indicated the increase in sensitivity to X-irradiation) was 1.51 for SCCVII, 1.28 for A549 and 1.25 for V79 cells. Furthermore, in SCCVII cells, this radiosensitization effect induced by GNG was dose-dependent (Supplemental Fig. 1). These results indicated that GNG increased radiosensitivity in the various cell lines.

To clarify the contribution made by apoptotic induction to the increased radiosensitivity of GNG-treated cells (Fig. 2A), we next undertook apoptosis detection by Annexin V-FITC/PI flow cytometry in SCCVII cells treated with a combination of GNG and X-irradiation. At $48 \mathrm{~h}$ after cells were treated with the combination of $15 \mathrm{~Gy}$ 
of X-irradiation and $20 \mu \mathrm{g} / \mathrm{ml} \mathrm{GNG}$, large number of cells were observed in the regions of the lower right quadrant (Annexin V-FITC $[+] / \mathrm{PI}[-])$ which represents early apoptosis, and upper right quadrant (Annexin V-FITC $[+] / \mathrm{PI}[+])$ which represents late apoptosis including necrosis, compared with control and X-irradiation alone groups (Fig. 2B[a]). As shown in Fig. 2B(b), the quantification result demonstrated that GNG treatment significantly enhanced X-ray-induced increase of both the Annexin V-FITC[+]/PI[-] early apoptosis cell population and the Annexin V-FITC $[+] / \mathrm{PI}[+]$ late apoptosis cell population. We also performed fluorescent detection of apoptosis by PI single staining.

Supplemental Fig.2 demonstrated that X-irradiation alone induced a slight increase in apoptosis in SCCVII cells. However, when cells were treated with X-rays plus GNG, the number of apoptotic cells increased significantly with time and reached $16.3 \pm 1.1 \%$ at $72 \mathrm{~h}$ after treatment. These results suggested that GNG enhanced reproductive cell death in X-irradiated cells partly through the induction of apoptosis.

\subsection{Physical dose absorption of gold nanoparticles in GNG}

Herold et al. demonstrated that gold particles with a diameter of 1.5-3.0 $\mu \mathrm{m}$ radiosensitized murine tumor cells because of the enhanced dose from electrons generated mainly by the photoelectric effect [5]. To determine whether or not the 
enhancement of physical dose by gold nanoparticles in GNG could contribute to the biological radiosensitizing effect, we performed Fricke chemical dosimetry. The Fricke solution with or without GNG was irradiated using various doses of X-rays. Fig. 3A shows the absorbed doses in the solution with time; there was no potentiation of dose enhancement as a result of the presence of $50 \mu \mathrm{g} / \mathrm{ml} \mathrm{GNG}$. As shown in Fig. 3B, dose rates calculated from linear regression analysis were 2.15, 2.21 and $2.23 \mathrm{~Gy} / \mathrm{min}$ for solutions with 0,20 and $50 \mu \mathrm{g} / \mathrm{ml} \mathrm{GNG}$, respectively. These results suggested that GNG at these concentrations shows little physical dose enhancement.

\subsection{Radiosensitizing effect of extracellular GNG}

To explore another mechanism of GNG-induced radiosensitization excluding physical dose enhancement, we attempted to determine whether or not the presence of extracellular GNG during X-irradiation was essential for radiosensitization. For this purpose, SCCVII cells was exposed to X-irradiation after the removal of GNG from the culture medium and clonogenic survival was evaluated. As shown in Fig. 4, significant radiosensitizing effects were observed to a similar extent, regardless of whether GNG was present in the culture medium during $\mathrm{X}$-irradiation or not. This result suggested that it was the GNG incorporated into cells that mainly contributed to the radiosensitizing 
effect, and this effect was hardly enhanced by extracellular GNG.

\subsection{Intracellular distribution of GNG and the induction of ER stress in cells}

To examine the intracellular distribution of GNG, the cytomorphological changes in SCCVII, A549 and V79 cells after treatment with GNG for $14 \mathrm{~h}$ were examined using TEM. As shown in Fig. 5A, GNG was incorporated into all the cell lines tested. In addition, GNG was not localized in the nucleus and only accumulated close to the nuclear membrane and in the cytoplasm. High magnification image revealed that GNG was located especially in the endosome/lysosome, and the intact structure of GNG consisting of gold nanoparticles (high contrast) and the cross-linked PEAMA gel core (low contrast) was preserved (Supplemental Fig. 3). The uptake of GNG into the endosome/lysosome continued to be observed even after exposure to X-rays (data not shown). This morphological data led us to speculate that GNG exposure induced ER stress in cells. Accordingly, we examined the protein expressions of several ER stress markers. Fig. 5B(a) shows that IRE1 $\alpha$ expression and PERK phosphorylation were clearly up-regulated in GNG-treated SCCVII cells. Furthermore, in A549 cells, GNG treatment increased the expressions of BiP/GRP78, Calnexin and Ero-1 $\alpha$, in addition to IRE-1 $\alpha$ (Fig. 5B[b]). 


\subsection{Suppression of DSB repair capacity by GNG}

To explore the involvement of cellular DNA repair in GNG-induced radiosensitization, we analyzed DSBs in X-irradiated cells by means of the $\gamma-\mathrm{H} 2 \mathrm{AX}$ foci formation assay; this assay measures the relative amount of DSBs and repair kinetics $[19,20]$. Fig. $6 \mathrm{~A}$ shows the temporal changes in the number of $\gamma$-H2AX foci in SCCVII cells after exposure to X-irradiation. When cells were irradiated at 1 Gy without GNG, there was a peak in the average number of $\gamma-\mathrm{H} 2 \mathrm{AX}$ foci per cell $(14.5 \pm 1.0)$ at 30 min after $\mathrm{X}$-irradiation followed by a decrease in number with time. However, treatment with $20 \mu \mathrm{g} / \mathrm{ml} \mathrm{GNG}$ induced a significantly higher number of foci with a maximum of $15.6 \pm 1.0$ at $1 \mathrm{~h}$ after $\mathrm{X}$-irradiation $(p=0.0237)$. In addition, the disappearance of the $\gamma$-H2AX foci was delayed, and even at $4 \mathrm{~h}$ a high number of foci (14.6 \pm 1.1$)$ remained. To investigate if the reduced DSB repair capacity detected in GNG-treated cells was attributable to the suppression of DSB repair-related proteins, we examined the effect of GNG treatment on the expression of Rad51 and Ku70, which are the key proteins in the HR and NHEJ pathways, respectively. SCCVII cells were treated with $20 \mu \mathrm{g} / \mathrm{ml} \mathrm{GNG}$ for $14 \mathrm{~h}$ and then their lysate was analyzed using immunoblotting. As shown in Fig. 6B, both Rad51 and Ku70 levels were decreased in 
SCCVII cells treated with GNG. These results suggested that GNG inhibited the expression of both HR- and NHEJ-related proteins, suppressing the repair capacity of radiation-induced DSBs. 


\section{Discussion}

For over two decades numerous methods for the delivery of a curative dose of radiation to tumor using high- $Z$ materials have been evaluated [7]. Among candidate high-Z materials for cancer radiotherapy, gold has some advantages; it absorbs $\sim 3$ times more X-ray energy than iodine at $100 \mathrm{keV}$, is relatively inert and can be biocompatible. The biocompatibility of gold is due to its ability to bind to amine and thiol groups, allowing surface modification and functionalization [21]. Our group has synthesized a novel PEGylated polyamine nanogel and established various biomedical applications of this nanogel as an endosomolytic carrier; these include gene delivery [22], siRNA delivery [23], drug delivery [24] and use as a ${ }^{19} \mathrm{~F}$ magnetic resonance spectroscopy nanoprobe [25]. In the present study we tested GNG, a novel nanogel agent containing gold nanoparticles [12], as a radiosensitizer. We found that GNG treatment enhanced not only reproductive cell death in all cell lines tested, but also apoptosis in SCCVII cells after X-irradiation. Apoptosis-mediated radiosensitization using gold nanoparticles has also been reported by Chang et al. [10]. Because the role of apoptosis in radiation-induced cell killing has been investigated and its significance as a predictor of tumor cell radiosensitivity is well known [26,27], GNG has the potential to improve the outcome of cancer radiotherapy. Interestingly, ICP-MS analysis for internalized ${ }^{197} \mathrm{Au}$ 
amounts demonstrated the relatively high uptake of GNG into SCCVII cells compared to V79 cells (Supplemental Fig.4), suggesting that this preferential uptake rate in tumor cells may reflect their higher radiosensitization effect observed in colony formation assay. Therefore, this result may indicate that GNG has the potential of being a tumor-specific agent. Importantly, in the present study the colony formation assay demonstrated the high cytotoxicity of the gold-free nanogel; the $50 \%$ inhibitory concentration $\left(\mathrm{IC}_{50}\right)$ values of the nanogel were 0.28 and $1.50 \mu \mathrm{g} / \mathrm{ml}$ in SCCVII and V79 cells respectively, compared with gold-containing nanogel $\left(\mathrm{IC}_{50}=80 \mu \mathrm{g} / \mathrm{ml}\right)$ (Supplemental Fig.5A). This result agrees with our previous result obtained using the WST assay, in which the PEGylated nanogel was found to be highly toxic to HeLa cells as compared with $\mathrm{GNG}(\mathrm{N} / \mathrm{Au}=2)$ [12]. In addition, the gold-free nanogel itself did not show any radiosensitization effect in SCCVII cells (Supplemental Fig.5B). Therefore, it is suggested that encapsulated gold particles ameliorate the cytotoxicity of the nanogel core and allow GNG to act as a sublethal radiosensitizer; however, the details involved remain to be elucidated.

In previous reports, radiation enhancement by gold particles has been believed to occur as a result of the interaction between X-rays and gold, predominantly by X-ray absorption through the photoelectic effect and Compton scattering [7]. However, at the 
concentrations used for biological radiosensitization, clear dose enhancement by GNG was not observed using Fricke chemical dosimetry. Furthermore, the numbers of $\gamma$-H2AX foci at peak after X-irradiation, indicating the initial DSBs did not differ significantly between the control and GNG-treated groups. These results suggest that GNG at doses of $20-50 \mu \mathrm{g} / \mathrm{ml}$ could not enhance the physical radiation dose and failed to potentiate radiation-induced DSB formation. Recently, radiation damage to cytoplasmic organelles (with the exception of nuclear DNA), such as mitochondria, has received much attention as a trigger for radiation-induced cell killing [28]. In the present study, clonogenic survival assays used to evaluate the sensitizing effect of GNG during $\mathrm{X}$-irradiation showed that it was its incorporation into cells that mainly contributed to its radiosensitizing properties. Furthermore, TEM analysis revealed that after uptake by endocytosis GNG was not distributed in the nucleus, but only in the endosome/lysosome. The accumulation in endosomes/lysosomes was demonstrated in our previous study using fluorescein-labeled doxorubicin incorporated in same PEAMA nanogel [24]. This cytoplasm-specific distribution of nanoscale gold particles has also been reported by other groups $[10,21,29]$. These findings imply the possibility that GNG sensitizes cells to X-rays not by inducing DNA damage but by affecting cytoplasmic organelles. In fact, Jain et al. demonstrated that the radiosensitization of 
tumor cells by gold nanoparticles was observed not only in the kilovoltage range but also in the megavoltage range, without an increase in DSB formation; hence they proposed that an unknown cellular mechanism was responsible rather than simple radiation dose enhancement [30].

The role of the UPR under ER stress in cell survival or cell death has been well studied [31]. The activation of UPR as a consequence of alteration of ER homeostasis and the subsequent accumulation of unfolded/misfolded proteins upregulates chaperon proteins to reduce the protein synthesis load, resulting in it having a cytoprotective function. However, under prolonged or excessive stress, UPR stimulates the proapoptotic cascade, leading to cell death. While this balance between cytoprotective and apoptotic responses during ER stress has not been fully elucidated, severe induction of UPR by overloading the ER capacity is assumed to enhance cellular sensitivity to chemotherapeutic agents or radiation. For example, cellular sensitivity to cisplatin was increased by the overexpression of GRP78, an abundant ER chaperon [32], or by treatment with tunicamycin, a chemical ER stress inducer [33]. Furthermore, cancer cells treated with acriflavin and also with tunicamycin have been reported to be sensitized to ionizing radiation through the activation of the UPR $[34,35,36]$. In the present study, GNG accumulated in cytoplasmic organelles and increased the 
expressions of several ER stress-related molecules such as IRE-1 $\alpha$, suggesting that GNG acted as an ER stress inducer and enhanced X-ray-induced apoptosis. This hypothesis may be supported by findings from previous studies that indicated that the PEGylated phospholipid nanomicelles [16] or epitaxial gold nanoparticles [37] induced ER stress and UPR signaling-dependent apoptosis in cancer cells. Chang et al. demonstrated that citrate-stabilized gold nanoparticles were localized in the ER and Golgi apparatus in melanoma cells, and that they increased the apoptotic potential of post-irradiated cells [10].

Interestingly, in the current study we found that the disappearance of the $\gamma-\mathrm{H} 2 \mathrm{AX}$ foci was significantly delayed in GNG-pretreated cells relative to control cells. Immunoblot analysis revealed that pretreatment with GNG decreased the expressions of Rad51 and $\mathrm{Ku} 70$, which are the key proteins in the HR and NHEJ pathways, respectively. These results suggested that GNG suppressed the cellular DSB repair capacity through the inhibition of both the HR and NHEJ pathways. The mechanism for this repression of DSB repair capacity remains unknown, but ER stress induced by GNG may be involved. Meng et al. demonstrated that chronic hypoxia, a physiological condition that induces ER stress, down-regulated both HR- and NHEJ-related proteins transcriptionally [38]. Other reports have also revealed that chronic hypoxia suppressed 
the expression of HR-related proteins, especially Rad51 and increased radiosensitivity $[39,40]$. In addition, we previously clarified that tunicamycin stimulated proteasomal degradation of Rad51, inhibited HR repair and enhanced the radiosensitivity of lung cancer cells [41]. These studies imply that GNG-induced radiosensitization could possibly be due to impaired DSB repair capacity as a result of ER stress. Further study is required to elucidate the precise mechanism underlying this radiosensitization.

In conclusion, we demonstrated that the novel compound GNG, consisting of PEGylated nanogel and gold nanoparticles, could considerably enhance cell radiosensitivity. Furthermore, our study provides the first evidence that this radiosensitization effect was due to the induction of apoptosis and the inhibition of DSB repair, in part as a consequence of GNG-mediated ER stress.

\section{Acknowledgements}

This work was supported, in part, by the JSPS KAKENHI, Japan (No. 25861045 [H.Y.], No. 23780286 [T.Y.] and No. 24659551 [O.I.]), by the Akiyama Life Science

Foundation [H.Y.] and by the Takeda Science Foundation [H.Y.]. 


\section{References}

[1] H. Matsudaira, A.M. Ueno, I. Furuno, Iodine contrast medium sensitizes cultured mammalian cells to X rays but not to gamma rays. Radiat. Res. 84 (1980) 144-148.

[2] R. Nath, P. Bongiorni, P.I. Rossi, S. Rockwell, Enhanced IUdR radiosensitization by 241Am photons relative to 226Ra and 125I photons at $0.72 \mathrm{~Gy} / \mathrm{hr}$. Int. J. Radiat. Oncol. Biol. Phys. 18 (1990) 1377-1385.

[3] E.E. Connor, J. Mwamuka, A. Gole, C.J. Murphy, M.D. Wyatt, Gold nanoparticles are taken up by human cells but do not cause acute cytotoxicity. Small 1 (2005) 325-327.

[4] R. Shukla, V. Bansal, M. Chaudhary, A. Basu, R.R. Bhonde, M. Sastry, Biocompatibility of gold nanoparticles and their endocytotic fate inside the cellular compartment: a microscopic overview. Langmuir 21 (2005) 10644-10654.

[5] D.M. Herold, I.J. Das, C.C. Stobbe, R.V. Iyer, J.D. Chapman, Gold microspheres: a selective technique for producing biologically effective dose enhancement. Int. J. Radiat. Biol. 76 (2000) 1357-1364.

[6] W.N. Rahman, N. Bishara, T. Ackerly, C.F. He, P. Jackson, C. Wong, R. Davidson, M. Geso, Enhancement of radiation effects by gold nanoparticles for superficial radiation therapy. Nanomedicine 5 (2009) 136-142.

[7] J.F. Hainfeld, F.A. Dilmanian, D.N. Slatkin, H.M. Smilowitz, Radiotherapy enhancement with gold nanoparticles. J. Pharm. Pharmacol. 60 (2008) 977-985.

[8] J.F. Hainfeld, D.N. Slatkin, H.M. Smilowitz, The use of gold nanoparticles to enhance radiotherapy in mice. Phys. Med. Biol. 49 (2004) N309-315.

[9] J.F. Hainfeld, H.M. Smilowitz, M.J. O'Connor, F.A. Dilmanian, D.N. Slatkin, Gold nanoparticle imaging and radiotherapy of brain tumors in mice. Nanomedicine (Lond.) 8 (2013) 1601-0609.

[10] M.Y. Chang, A.L. Shiau, Y.H. Chen, C.J. Chang, H.H. Chen, C.L. Wu, Increased apoptotic potential and dose-enhancing effect of gold nanoparticles in combination with single-dose clinical electron beams on tumor-bearing mice. Cancer Sci. 99 (2008) 1479-1484.

[11] C.J. Liu, C.H. Wang, S.T. Chen, H.H. Chen, W.H. Leng, C.C. Chien, C.L. Wang, I.M. Kempson, Y. Hwu, T.C. Lai, M. Hsiao, C.S. Yang, Y.J. Chen, G. Margaritondo, Enhancement of cell radiation sensitivity by pegylated gold nanoparticles. Phys. Med. Biol. 55 (2010) 931-945.

[12] T. Nakamura, A. Tamura, H. Murotani, M. Oishi, Y. Jinji, K. Matsuishi, Y. Nagasaki, Large payloads of gold nanoparticles into the polyamine network core of stimuli-responsive PEGylated nanogels for selective and noninvasive cancer photothermal therapy. Nanoscale 2 (2010) 739-746.

[13] M. Oishi, Y. Nagasaki, Synthesis, characterization, and biomedical applications of core-shell-type stimuli-responsive nanogels - Nanogel composed of 
poly[2-(N,N-diethylamino)ethyl methacrylate] core and PEG tethered chains. React. Func. Polym. 67 (2007) 1311-1329.

[14] Y. Pan, A. Leifert, D. Ruau, S. Neuss, J. Bornemann, G. Schmid, W. Brandau, U. Simon, W. Jahnen-Dechent, Gold nanoparticles of diameter $1.4 \mathrm{~nm}$ trigger necrosis by oxidative stress and mitochondrial damage. Small 5 (2009) 2067-2076.

[15] W. Roa, X. Zhang, L. Guo, A. Shaw, X. Hu, Y. Xiong, S. Gulavita, S. Patel, X. Sun, J. Chen, R. Moore, J.Z. Xing, Gold nanoparticle sensitize radiotherapy of prostate cancer cells by regulation of the cell cycle. Nanotechnology 20 (2009) 375101.

[16] J. Wang, X. Fang, W. Liang, Pegylated phospholipid micelles induce endoplasmic reticulum-dependent apoptosis of cancer cells but not normal cells. ACS Nano 6 (2012) 5018-5030.

[17] T. Helleday, E. Petermann, C. Lundin, B. Hodgson, R.A. Sharma, DNA repair pathways as targets for cancer therapy. Nat. Rev. Cancer 8 (2008) 193-204.

[18] H. Yasui, O. Inanami, T. Asanuma, D. Iizuka, T. Nakajima, Y. Kon, A. Matsuda, M. Kuwabara, Treatment combining X-irradiation and a ribonucleoside anticancer drug, TAS106, effectively suppresses the growth of tumor cells transplanted in mice. Int. J. Radiat. Oncol. Biol. Phys. 68 (2007) 218-228.

[19] S. Meike, T. Yamamori, H. Yasui, M. Eitaki, A. Matsuda, M. Morimatsu, M. Fukushima, Y. Yamasaki, O. Inanami, A nucleoside anticancer drug, 1-(3-C-ethynyl-beta-D-ribo-pentofuranosyl)cytosine (TAS106), sensitizes cells to radiation by suppressing BRCA2 expression. Mol. Cancer 10 (2011) 92.

[20] E.P. Rogakou, D.R. Pilch, A.H. Orr, V.S. Ivanova, W.M. Bonner, DNA double-stranded breaks induce histone H2AX phosphorylation on serine 139. J. Biol. Chem. 273 (1998) 5858-5868.

[21] S. Jain, D.G. Hirst, J.M. O'Sullivan, Gold nanoparticles as novel agents for cancer therapy. Br. J. Radiol. 85 (2012) 101-113.

[22] M. Oishi, pH-Responsive PEGylated nanogels as targetable and low invasive endosomolytic agents to induce the enhanced transfection efficiency of nonviral gene vectors. Colloid and polymer science 285 (2007) 1055-1060.

[23] A. Tamura, M. Oishi, Y. Nagasaki, Efficient siRNA delivery based on PEGylated and partially quaternized polyamine nanogels: enhanced gene silencing activity by the cooperative effect of tertiary and quaternary amino groups in the core. J. Control Release 146 (2010) 378-387.

[24] M. Oishi, H. Hayashi, M. Iijima, Y. Nagasaki, Endosomal release and intracellular delivery of anticancer drugs using pH-sensitive PEGylated nanogels. J. Mater. Chem. 17 (2007) 3720-3725.

[25] M. Oishi, S. Sumitani, T.K. Bronich, A.V. Kabanov, M.D. Boska, Y. Nagasaki, Novel 19F MRS/I Nanoprobe Based on pH-Responsive PEGylated Nanogel: pH-Dependent 19F Magnetic Resonance Studies. Chem. Lett. 38 (2009) 128-129. 
[26] B.A. Rupnow, A.D. Murtha, R.M. Alarcon, A.J. Giaccia, S.J. Knox, Direct evidence that apoptosis enhances tumor responses to fractionated radiotherapy. Cancer Res. 58 (1998) 1779-1784.

[27] B. Zhivotovsky, B. Joseph, S. Orrenius, Tumor radiosensitivity and apoptosis. Exp. Cell. Res. 248 (1999) 10-17.

[28] K.M. Prise, G. Schettino, M. Folkard, K.D. Held, New insights on cell death from radiation exposure. Lancet Oncol. 6 (2005) 520-528.

[29] D.B. Chithrani, S. Jelveh, F. Jalali, M. van Prooijen, C. Allen, R.G. Bristow, R.P. Hill, D.A. Jaffray, Gold nanoparticles as radiation sensitizers in cancer therapy. Radiat. Res. 173 (2010) 719-728.

[30] S. Jain, J.A. Coulter, A.R. Hounsell, K.T. Butterworth, S.J. McMahon, W.B. Hyland, M.F. Muir, G.R. Dickson, K.M. Prise, F.J. Currell, J.M. O'Sullivan, D.G. Hirst, Cell-specific radiosensitization by gold nanoparticles at megavoltage radiation energies. Int. J. Radiat. Oncol. Biol. Phys. 79 (2011) 531-539.

[31] Y. Ma, L.M. Hendershot, The role of the unfolded protein response in tumour development: friend or foe? Nat. Rev. Cancer 4 (2004) 966-977.

[32] S. Chatterjee, H. Hirota, C.A. Belfi, S.J. Berger, N.A. Berger, Hypersensitivity to DNA cross-linking agents associated with up-regulation of glucose-regulated stress protein GRP78. Cancer Res. 57 (1997) 5112-5116.

[33] I. Noda, S. Fujieda, M. Seki, N. Tanaka, H. Sunaga, T. Ohtsubo, H. Tsuzuki, G.K. Fan, H. Saito, Inhibition of N-linked glycosylation by tunicamycin enhances sensitivity to cisplatin in human head-and-neck carcinoma cells. Int. J. Cancer 80 (1999) 279-284.

[34] J.N. Contessa, M.S. Bhojani, H.H. Freeze, A. Rehemtulla, T.S. Lawrence, Inhibition of N-linked glycosylation disrupts receptor tyrosine kinase signaling in tumor cells. Cancer Res. 68 (2008) 3803-3809.

[35] M.J. Lim, J.Y. Ahn, Y. Han, C.H. Yu, M.H. Kim, S.L. Lee, D.S. Lim, J.Y. Song, Acriflavine enhances radiosensitivity of colon cancer cells through endoplasmic reticulum stress-mediated apoptosis. Int. J. Biochem. Cell. Biol. 44 (2012) 1214-1222.

[36] X.L. Pang, G. He, Y.B. Liu, Y. Wang, B. Zhang, Endoplasmic reticulum stress sensitizes human esophageal cancer cell to radiation. World J. Gastroenterol. 19 (2013) 1736-1748.

[37] Y.Y. Tsai, Y.H. Huang, Y.L. Chao, K.Y. Hu, L.T. Chin, S.H. Chou, A.L. Hour, Y.D. Yao, C.S. Tu, Y.J. Liang, C.Y. Tsai, H.Y. Wu, S.W. Tan, H.M. Chen, Identification of the nanogold particle-induced endoplasmic reticulum stress by omic techniques and systems biology analysis. ACS Nano 5 (2011) 9354-9369.

[38] A.X. Meng, F. Jalali, A. Cuddihy, N. Chan, R.S. Bindra, P.M. Glazer, R.G. Bristow, Hypoxia down-regulates DNA double strand break repair gene expression in prostate cancer cells. 
Radiother. Oncol. 76 (2005) 168-176.

[39] R.S. Bindra, P.J. Schaffer, A. Meng, J. Woo, K. Maseide, M.E. Roth, P. Lizardi, D.W. Hedley, R.G. Bristow, P.M. Glazer, Down-regulation of Rad51 and decreased homologous recombination in hypoxic cancer cells. Mol. Cell. Biol. 24 (2004) 8504-8518.

[40] N. Chan, M. Koritzinsky, H. Zhao, R. Bindra, P.M. Glazer, S. Powell, A. Belmaaza, B. Wouters, R.G. Bristow, Chronic hypoxia decreases synthesis of homologous recombination proteins to offset chemoresistance and radioresistance. Cancer Res. 68 (2008) 605-614.

[41] T. Yamamori, S. Meike, M. Nagane, H. Yasui, O. Inanami, ER stress suppresses DNA double-strand break repair and sensitizes tumor cells to ionizing radiation by stimulating proteasomal degradation of Rad51. FEBS Letters 587 (2013) 3348-3353. 


\section{Figure legends}

\section{Fig. 1.}

Schematic illustration of the PEGylated nanogel containing gold nanoparticle (GNG).

\section{Fig. 2.}

Effect of GNG on cellular radiosensitivity and the induction of apoptosis in tumor and immortalized cells. (A) Clonogenic survival curves obtained from (a) SCCVII, (b) A549 and (c) V79 cell lines. The treatment with GNG at doses of 20, 15 and $50 \mu \mathrm{g} / \mathrm{ml}$ was performed for $14 \mathrm{~h}$ before X-irradiation of SCCVII, A549 and V79 cells, respectively. Cells were exposed to X-rays in the presence of GNG and assessed for radiosensitizing effects using a colony formation assay. $\bigcirc: \mathrm{X}$-irradiation alone, $\mathrm{X}$-irradiation + GNG pretreatment. (B) The apoptosis induction by the combined treatment with X-irradiation and GNG was examined by flow cytometric analysis for Annexin V-FITC and PI. At $48 \mathrm{~h}$ after SCCVII cells were treated with X-irradiation and/or GNG, cells were stained with Annexin V-FITC and PI, and then analyzed for their fluorescence by flow cytometer. (a) Representative fluorescence dot blots of Annexin V- and PI-stained cells. The lower right quadrant (Annexin V-FITC[+]/PI[-]) 
and the upper right quadrant (Annexin $\mathrm{V}-\mathrm{FITC}[+] / \mathrm{PI}[+]$ ) represent early apoptosis, and late apoptosis including necrosis, respectively. (b) The quantification result obtained from fluorescence dot blots. Open column: early apoptosis, closed column: late apoptosis including necrosis. Data are expressed as the mean $\pm \mathrm{SE}$ for three experiments. $* p<0.01$, significant difference vs. X-rays alone.

\section{Fig. 3.}

Physical dose enhancement by the gold nanoparticles incorporated into GNG. (A) The dose delivered to Fricke solutions containing 0 (०) and $50 \mu \mathrm{g} / \mathrm{ml}$ (घ) GNG irradiated for a range of exposure times with $200 \mathrm{keV}$ X-rays. Data are expressed as mean $\pm \mathrm{SE}$ for three experiments. (B) Dose rate calculated from the X-ray absorption dose in Fricke solutions containing 0,20 and $50 \mu \mathrm{g} / \mathrm{ml} \mathrm{GNG}$.

\section{Fig. 4.}

Contribution of extracellular GNG to the radiosensitization of SCCVII cells.

Dose-response curve for SCCVII cells exposed to X-rays in the presence or absence of GNG. ○: X-irradiated cells, m: Cells treated with $20 \mu \mathrm{g} / \mathrm{ml} \mathrm{GNG}$ before X-irradiation, 
$\square$ : Cells treated with $20 \mu \mathrm{g} / \mathrm{ml} \mathrm{GNG} \mathrm{before} \mathrm{and} \mathrm{during} \mathrm{X-irradiation.} \mathrm{Data} \mathrm{are} \mathrm{expressed}$ as the mean $\pm \mathrm{SE}$ for three experiments.

\section{Fig. 5.}

GNG distribution in cytoplasmic organelles and ER stress induction in tumor or immortalized cells. (A) TEM images of (a) SCCVII, (b) A549 and (c) V79 cells treated with GNG for $14 \mathrm{~h}$ at low (left panels) and high (right panels) magnifications. Incorporated GNGs into cytoplasm is indicated by arrow head. (B) Immunoblot of the expression of IRE1 $\alpha$ in SCCVII cells treated with or without GNG. Actin was used as an internal control.

Fig. 6.

The effect of GNG on the DNA repair capacity in SCCVII cells. (A) $\gamma-\mathrm{H} 2 \mathrm{AX}$ foci formation after X-irradiation. Cells were pretreated with $20 \mu \mathrm{g} / \mathrm{ml} \mathrm{GNG}$ for $14 \mathrm{~h}$, followed by X-rays at a single dose of 1 Gy. They were then fixed at the indicated times and stained to evaluate the nuclear $\gamma-\mathrm{H} 2 \mathrm{AX}$ foci formation and kinetics. The numbers of foci in at least 20 cells were scored and the average numbers have been plotted on the graph. Data are expressed as the mean \pm SE of three experiments. ${ }^{*} p<0.05$, significant 
difference vs. no GNG treatment. (B) Immunoblots of the expressions of Rad51 and $\mathrm{Ku} 70$ in SCCVII cells treated with or without GNG. SCCVII cells were treated with 20 $\mu \mathrm{g} / \mathrm{ml} \mathrm{GNG}$ for $14 \mathrm{~h}$. In the middle panel, the upper bands represent $\mathrm{Ku} 70$ protein and the lower bands are nonspecific, indicated by the positive control A549 lysate. Actin was used as an internal control. 


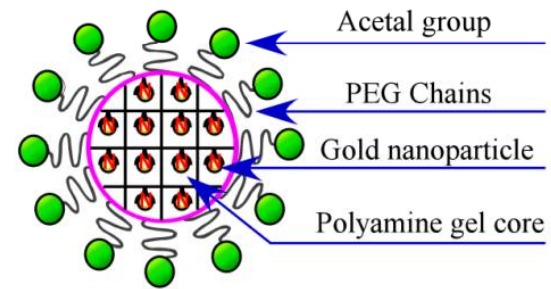

Figure 1. Yasui et al. 


\section{A(a) SCCVII}

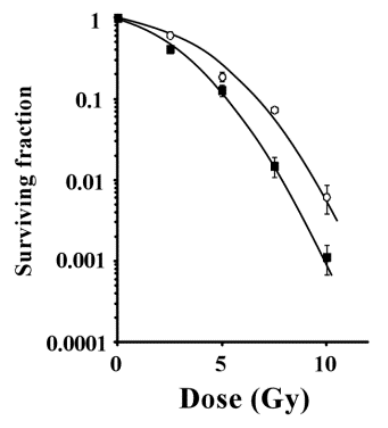

- - GNG

— + GNG (20 $\mu \mathrm{g} / \mathrm{ml})$ (b) $\mathbf{A 5 4 9}$

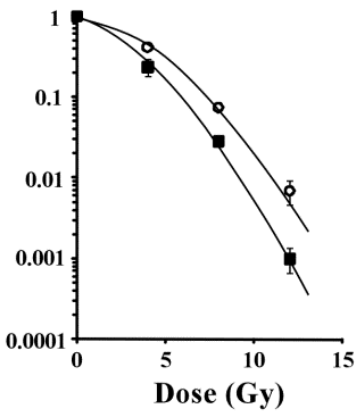

- - GNG

- + GNG $(15 \mu \mathrm{g} / \mathrm{ml})$ (c) V79

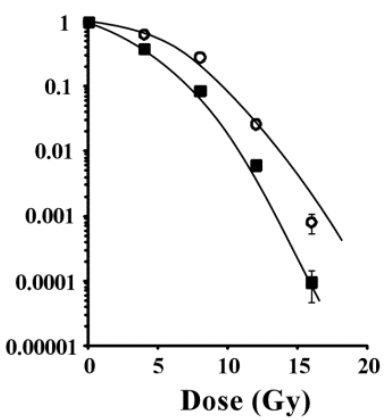

- - GNG

口 + GNG (50 $\mu \mathrm{g} / \mathrm{ml})$

\section{B(a)}

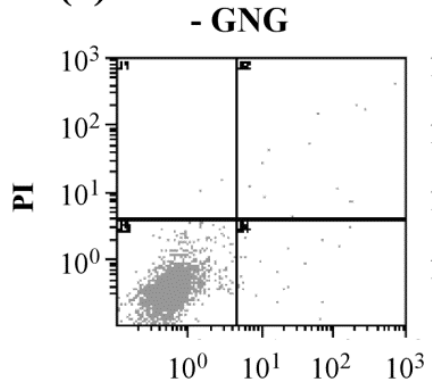

Annexin V-FITC

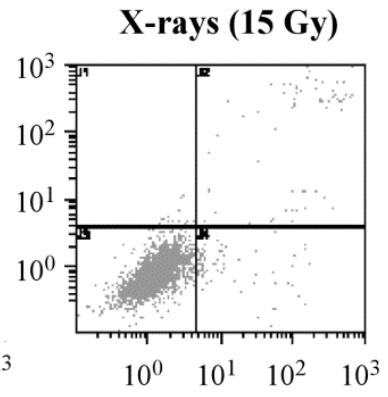

X-rays + GNG (20 $\mu \mathrm{g} / \mathrm{ml})$

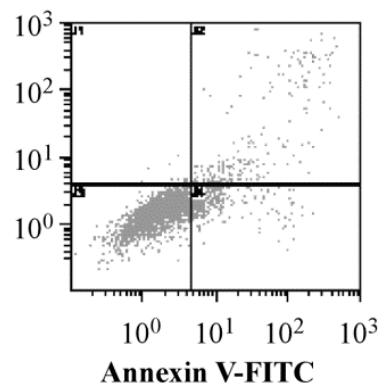

(b)

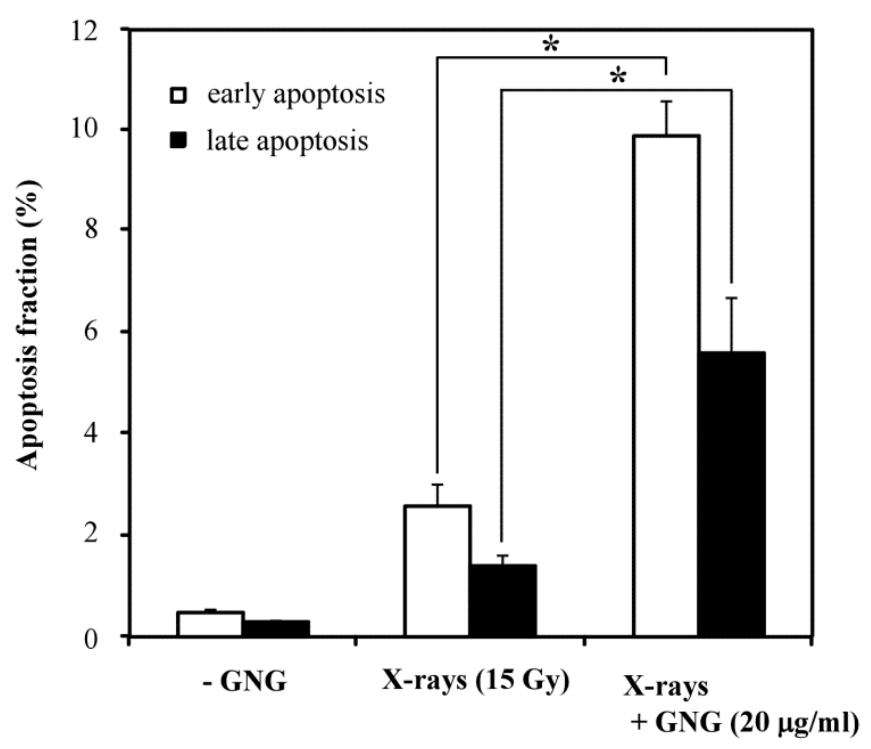

Figure 2. Yasui et al. 
A

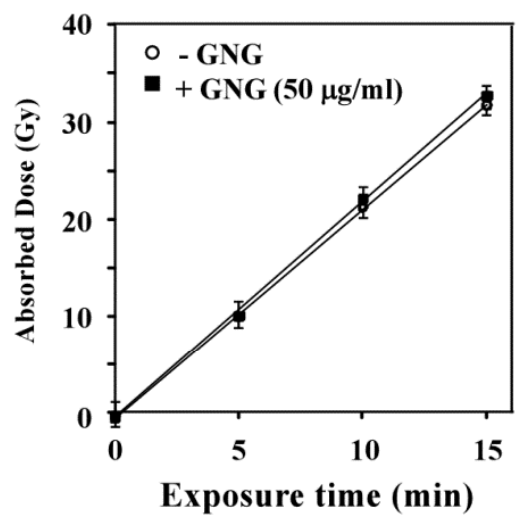

B

\begin{tabular}{|l|l}
\hline GNG concentration & Dose rate \\
\hline
\end{tabular}

\begin{tabular}{|c|c|}
\hline $0 \mu \mathrm{g} / \mathrm{ml}$ & $2.15 \mathrm{~Gy} / \mathrm{min}$ \\
\hline \hline
\end{tabular}

$20 \mu \mathrm{g} / \mathrm{ml}$ $2.21 \mathrm{~Gy} / \mathrm{min}$

$50 \mu \mathrm{g} / \mathrm{ml}$ $2.23 \mathrm{~Gy} / \mathrm{min}$

Figure 3. Yasui et al. 


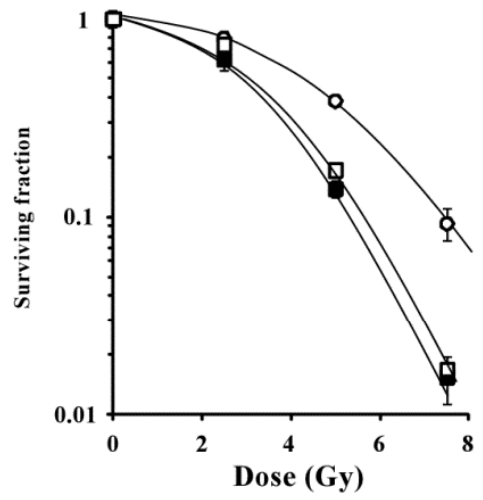

○ X-irradiation

- GNG treatment before $\mathrm{X}$-irradiation

$\square$ GNG treatment before and during $X$-irradiation

Figure 4. Yasui et al. 


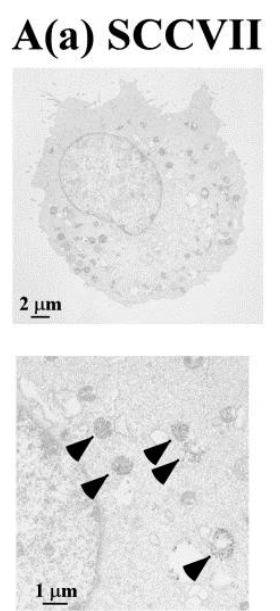

B (a) SCCVII (b) $\mathrm{A549}$
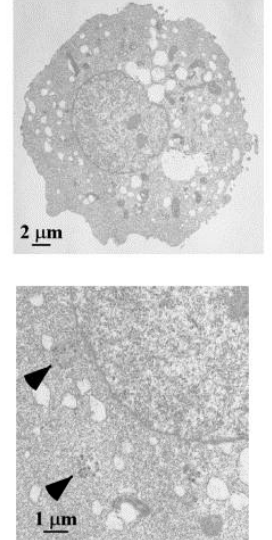

(c) V79
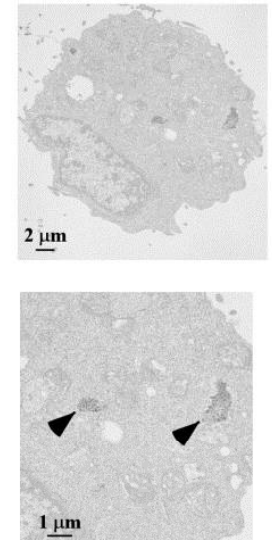

(b) $\mathrm{A549}$

$$
\begin{aligned}
& \text { GNG - }+ \\
& \text { IRE1 } \alpha \text { en }
\end{aligned}
$$

IRE $1 \alpha /$ Actin ratio

BiP

$\mathrm{BiP} /$ Actin ratio

p-PERK

PERK

p-PERK/PERK ratio

Actin
$1 \quad 1.39$

$1 \quad 1.03$

wei inat

$1 \quad 1.52$

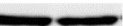

GNG $\quad-\quad+$

IRE1 $\alpha$ №

IRE $1 \alpha /$ Actin ratio $\quad 1 \quad 1.60$

BiP

BiP/Actin ratio 11.52

Calnexin — -

Calnexin/Actin ratio $\quad 1 \quad 1.57$

Ero1-L $\alpha-$

Erol-L $\alpha /$ Actin ratio $\quad 1 \quad 1.53$

Actin

Figure 5. Yasui et al. 
A

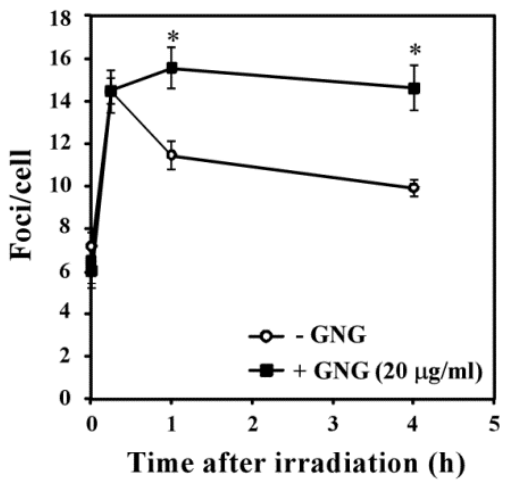

B

SCCVII lysate

Ku70

Figure 6. Yasui et al. 


\section{Supplemental material}

\section{Radiosensitization of tumor cells through endoplasmic reticulum stress induced by PEGylated nanogel containing gold nanoparticles}

\section{S1. Supplemental methods}

\section{S1.1. Assessment of cellular GNG uptake by ICP-MS}

After the treatment with GNG for the indicated periods, SCCVII or V79 cells were harvested, collected, and washed twice with PBS. All cell suspensions $\left(3 \times 10^{5}\right.$ cells) in $1 \mathrm{ml}$ PBS were digested with $4 \mathrm{ml}$ of aqua regia (liquid mixture of nitric acid conc. and hydrochloric acid conc. at a 1: 3 volume ratio) using microwave (Speed Wave MWS-2, Berghof, Germany). A ramped temperature control program was applied: ramp to $140^{\circ} \mathrm{C}$ ( $8 \mathrm{~min}$ hold), increasing to $160^{\circ} \mathrm{C}$ and hold for $15 \mathrm{~min}$, increase again to $200^{\circ} \mathrm{C}$ and hold for $20 \mathrm{~min}$. After cooling, samples were transferred into plastic tubes and made a final volume of $10 \mathrm{ml}$ with Milli Q-water. Blank samples were also carried out in the same way. The levels of gold were measured with an inductively coupled plasma-mass spectrometer (ICP-MS; 7700 series, Agilent technologies, Santa Clara, CA, USA). The quantification was carried out by external six-point-calibration with internal standard correction. The main instrumental operating conditions were as follows: RF power $1500 \mathrm{~W}$, Aux gas flow 1.0 L/min Ar and plasma gas flow $15 \mathrm{~L} / \mathrm{min}$ Ar. The following isotopes were measured: ${ }^{197} \mathrm{Au}$ and ${ }^{205} \mathrm{Tl}$ as internal standard. The detection limit and quantification limit were calculated from the slope and SD value of the $y$ intercept. Calculated detection and quantification limit were $1.2 \mathrm{ppb}$ and $3.5 \mathrm{ppb}$, respectively.

\section{S1.2. Fluorescent observation of apoptotic cells}

SCCVII cells incubated for the indicated periods after GNG treatment and $\mathrm{X}$-irradiation were collected by trypsinization and centrifugation. Cells were fixed and stained with $40 \mu \mathrm{g} / \mathrm{ml}$ propidium iodide. Fluorescent observation was performed under an Olympus BX50 microscope (Olympus, Tokyo, Japan). The fraction of apoptotic cells was calculated as the percentage of apoptotic cells relative to the total cell population. 


\section{S2. Supplemental results}

\section{S2.1. Dose-dependency of GNG-induced radiosensitization}

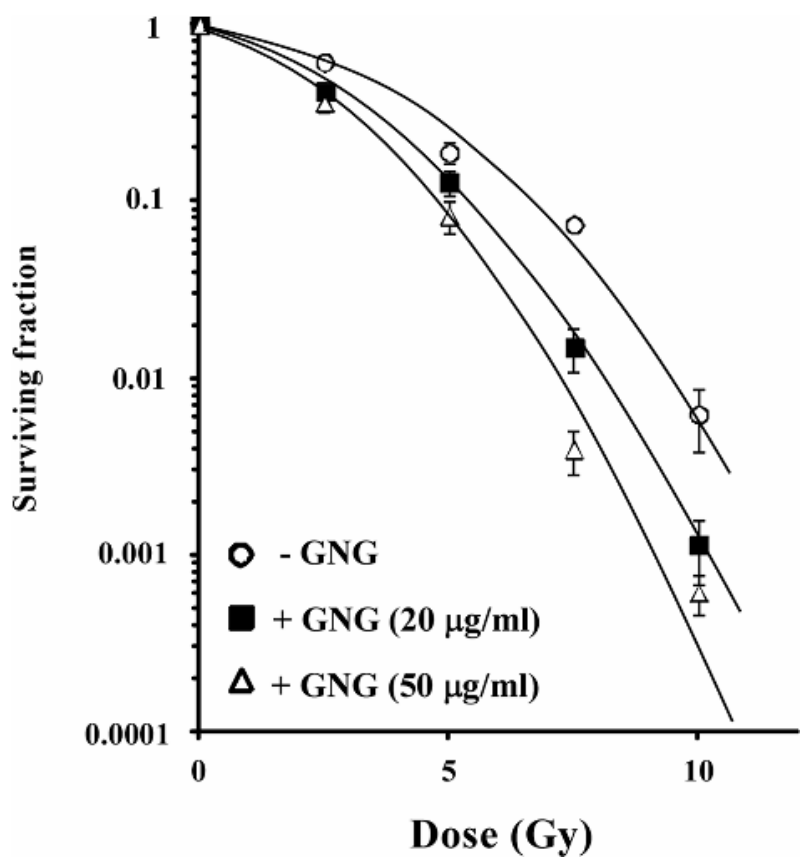

We tested two doses of GNG (20 and $50 \mu \mathrm{g} / \mathrm{ml}$ ) to investigate a dose-dependent radiosensitization. While relative high toxicity (plating efficiency $=0.55$ ) was observed in $50 \mu \mathrm{g} / \mathrm{ml}$ group compare to $20 \mu \mathrm{g} / \mathrm{ml}$ group (plating efficiency $=0.75$ ), this high dose of GNG showed higher radiosensitization effect. Data are expressed as the mean $\pm \mathrm{SE}$ for three experiments. 


\section{S2.2. The effect of GNG on apoptosis induction}

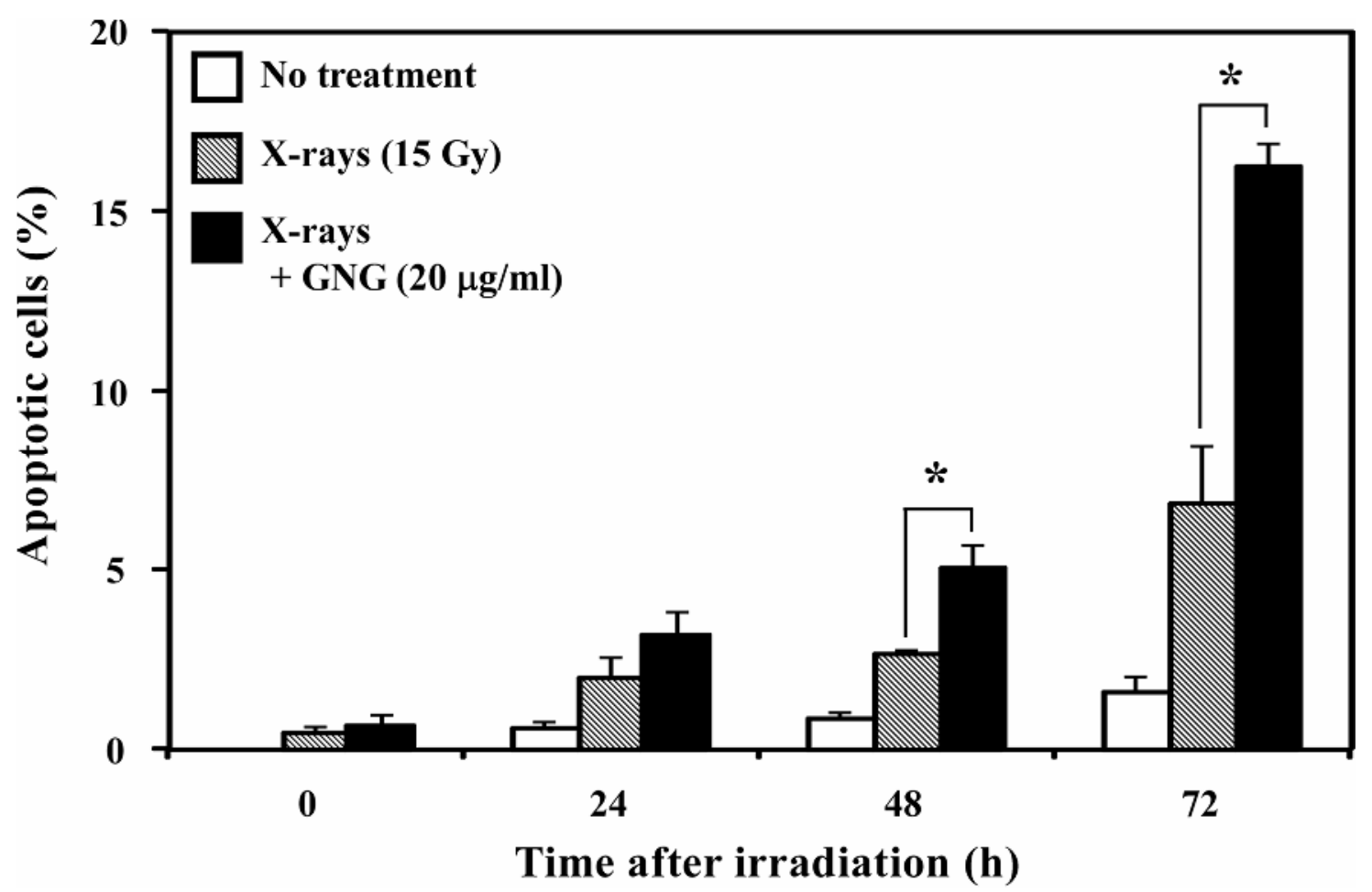

Temporal induction of apoptosis in SCCVII cells treated with 15 Gy of X-rays and/or $20 \mu \mathrm{g} / \mathrm{ml} \mathrm{GNG}$. At 0, 24, 48 and $72 \mathrm{~h}$ after treatment, apoptotic cells (\%) were counted under fluorescence microscopy after staining of cells with PI. Gradual increase of apoptosis with time was observed in all groups, but apoptosis induction in the combination group at 48 and $72 \mathrm{~h}$ was significantly higher than that in X-irradiation alone group. Open column: no treatment, gray column: $\mathrm{X}$-irradiation alone, closed column: $\mathrm{X}$-irradiation $+\mathrm{GNG}$ pretreatment. Data are expressed as the mean $\pm \mathrm{SE}$ for three experiments. ${ }^{*} \mathrm{p}<0.01$, significant difference vs. X-rays alone. 


\section{S2.3. The distribution of intact GNG in the endosome/ lysosome}

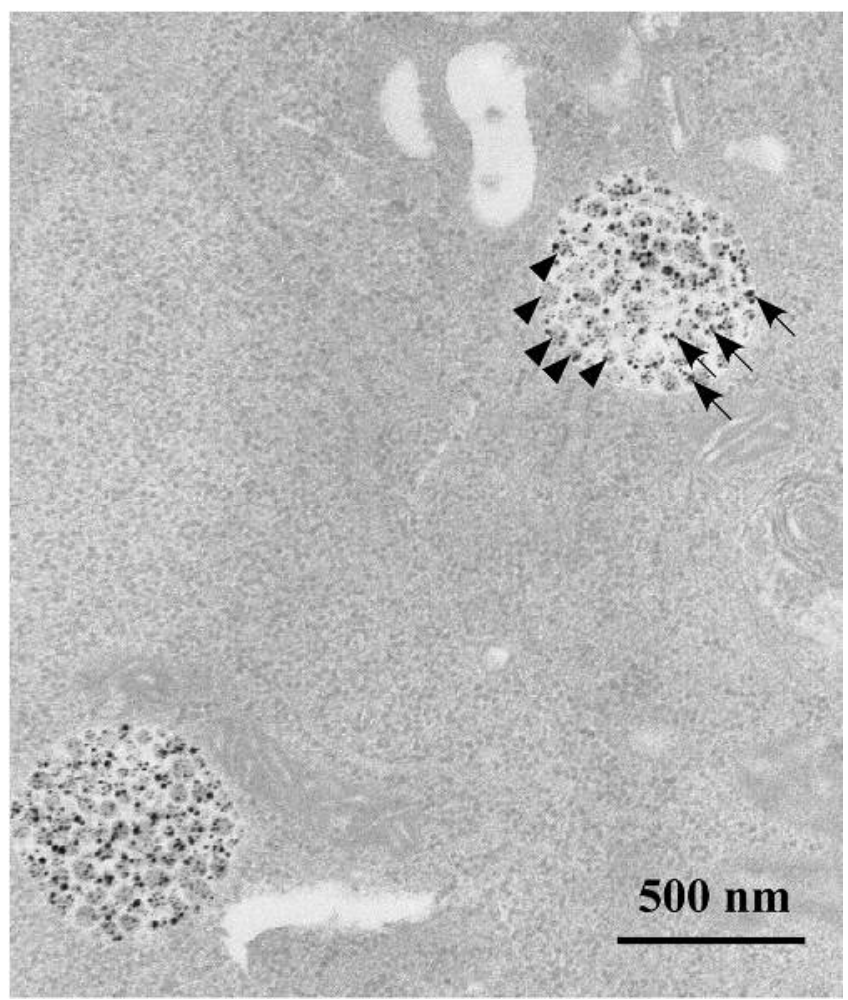

TEM image at high magnification in SCCVII cells treated with GNG for $14 \mathrm{~h}$. The gold nanoparticles (black dot indicated by arrow) localized in the cross-linked PEAMA gel core (gray globule indicated by arrow head) were observed in the endosomes/lysosomes. 
S2.4. The difference of cellular uptake of GNG into between cancer and immortalized normal cells

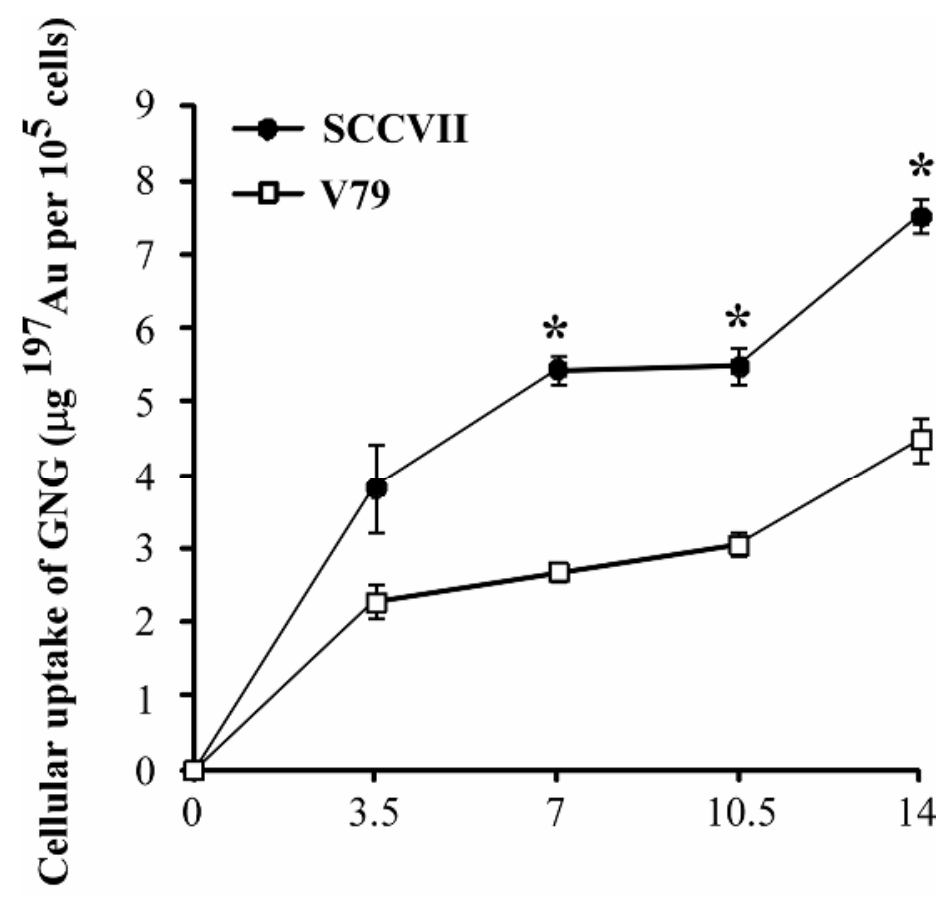

GNG treatment time (h)

To explore the amounts of gold-particle internalized in tumor and immortalized cells, GNG-treated cells collected after specific exposure periods of up to 14 hours, and then cells were lysed and analyzed by ICP-MS. In both cell lines, the amounts of ${ }^{197} \mathrm{Au}$ gradually increased with incubation time, but the values in SCCVII cells were higher than those in V79 cells. This result suggested the preferential uptake of GNG into tumor cells compared to immortalized cells. Data are expressed as the mean $\pm \mathrm{SE}$ for three experiments. ${ }^{*} \mathrm{p}<0.01$, significant difference vs. V79 cells. 


\section{S2.5. Effect of gold-free nanogel on cell survival and radiosensitivity}
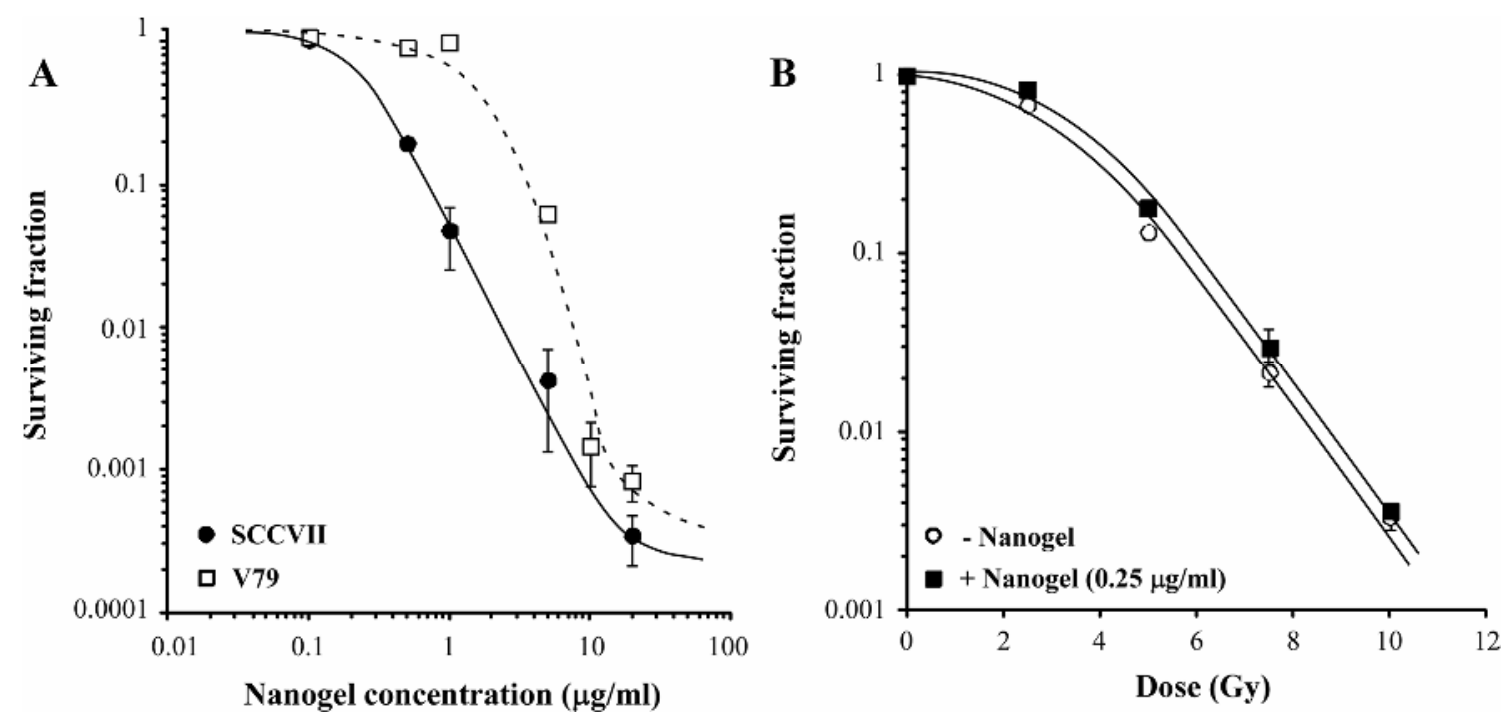

We examined the cytotoxicity of gold-free nanogel by colony formation assay in SCCVII and V79 cells. As shown in Supplemental Fig. 5A, the 50\% inhibitory concentration $\left(\mathrm{IC}_{50}\right)$ values of the nanogel were 0.28 and $1.50 \mu \mathrm{g} / \mathrm{ml}$ in SCCVII and V79 cells respectively, indicating high cytotoxicities compared to gold-containing nanogel $\left(\mathrm{IC}_{50}=80 \mu \mathrm{g} / \mathrm{ml}\right)$. In addition, the gold-free nanogel at a sublethal concentration of $0.25 \mu \mathrm{g} / \mathrm{ml}$ did not show any radiosensitization effect in SCCVII cells (Supplemental Fig. 5B). Data are expressed as the mean $\pm \mathrm{SE}$ for three experiments. 